\title{
Correction to: Artificial intelligence in assessment of hepatocellular carcinoma treatment response
}

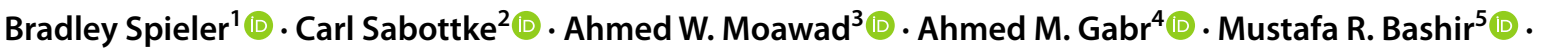

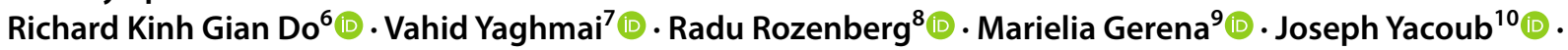 \\ Khaled M. Elsayes ${ }^{11}$ (1)
}

Published online: 24 May 2021

๑) Springer Science+Business Media, LLC, part of Springer Nature 2021

\section{Correction to: Abdominal Radiology} https://doi.org/10.1007/s00261-021-03056-1

The original version of this article unfortunately contained errors in the table 1 . The correct Table 1 is given below.

Bradley Spieler

bspie1@1suhsc.edu

Carl Sabottke

cfs121090@gmail.com

Ahmed W. Moawad

awmoawad@gmail.com

Ahmed M. Gabr

aamgabr@gmail.com

Mustafa R. Bashir

mustafa.bashir@duke.edu

Richard Kinh Gian Do

dok@mskcc.org

Vahid Yaghmai

vyaghmai@hs.uci.edu

Radu Rozenberg

radurosenberg@yahoo.com

Marielia Gerena

marielia.gerena@1umc.edu

Joseph Yacoub

joeyacoub@gmail.com

Khaled M. Elsayes

KMElsayes@mdanderson.org

1 Department of Radiology, Louisiana State University

Health Sciences Center, 1542 Tulane Avenue, Rm 343,

New Orleans, LA 70112, USA
2 Department of Medical Imaging, College of Medicine, University of Arizona, P.O. Box 245067, Tucson, AZ 85724-5067, USA

3 Department of Imaging Physics, College of Medicine, The University of Texas, P.O. Box 301402, Houston, TX 77230-1402, USA

4 Department of Interventional Radiology, OHSU and Tanta University, Egypt, 3181 SW Sam Jackson Park Road, Portland, OR 97239-3011, USA

5 Department of Radiology, Duke University Medical Center, Box 3808, Durham, NC 27710, USA

6 Department of Radiology, 300 East 66th Street Floors 5-6, New York, NY 10065, USA

7 Department of Radiology, University of California, Irvine, 101 City Drive South Bldg. 1, Rt. 140, Orange, CA 92868, USA

8 Department of Radiology, Thunder Bay Regional Health Sciences Centre, 980 Oliver Road, Thunder Bay, ON, Canada

9 Department of Radiology and Medical Imaging, Loyola University Medical Center, 2160 S. First Ave, Maywood, IL 60153, USA

10 Department of Radiology, Georgetown University, 3800 Reservoir Rd NW, Washington, DC 20007, USA

11 Department of Abdominal Imaging, University of Texas MD Anderson Cancer Center, 1400 Pressler St, Houston, TX 77030, USA 
Table 1 Summary of the 2018 version of the LI-RADS TRA four treatment response categories

\begin{tabular}{ll}
\hline Response category & Characteristics \\
\hline LR-TR Nonevaluable & Cannot evaluate due to image degradation or omission \\
LR-TR Nonviable & No lesional enhancement OR \\
& A treatment-specific expected enhancement pattern \\
LR-TR Equivocal & Enhancement atypical for treatment-specific expected enhancement pattern and not meeting criteria \\
& for probably or definitely viable \\
LR-TR Viable & Nodular, mass-like, or thick irregular tissue in or along the treated lesion with any of the following: \\
& 1. APHE \\
& 2. Washout appearance \\
& 3. Enhancement similar to pre-treatment \\
\hline
\end{tabular}

Publisher's Note Springer Nature remains neutral with regard to jurisdictional claims in published maps and institutional affiliations. 